\title{
Literary and Philosophical Heritage of Symbolism (on Problem of Searching for Truth)
}

\author{
Evgeny Korobeinikov*, Denis Khabibulin, Evgeny Tsapov, and Olesya Golubeva \\ Nosov Magnitogorsk State Technical University, 455000, Lenin av., 38, Magnitogorsk Russia
}

\begin{abstract}
This paper examines the cultural heritage of the end of the $19^{\text {th }}$ - the beginning of the $20^{\text {th }}$ century, which period is known for the crisis that struck all the spheres of life of the time - social and economic, political, philosophical, aesthetic. It is for this reason that the intellectuals of the time reflected on the crisis in their artistic, philosophical and spiritual search. In particular, this can be traced in the works of Russian and foreign modernists. In that period, the problem of creative cognition as a special ideology and a way to create life becomes of particular importance. The relevance of this work is defined by striving to outline certain approaches to solving this problem. The aim of this research is to identify the particularities of the subject-object relationship and how it forms in a literary work while enabling the author to build an adequate symbolist picture of the world, to transform and create it. The aspect examined by the authors of this article will help analyse the system of symbolism, just like any other theory, from the philosophical standpoint. One can use the results of this research when developing new programmes for basic and special courses in the history of 20th-century Russian literature and culture to be taught at university or at school.
\end{abstract}

The problem of identifying the specific features of creative cognition, which has undergone a long period of evolution - from the theory of imitation of nature in the ancient world to the theory of reflection of reality in the $20^{\text {th }}$ century, - is of extreme relevance even today $[1,2$, $3,4,5]$. And it is in symbolism that this problem is given a special focus and an original interpretation. Many aspects of this problem are yet to reveal themselves in full, especially in the practical implementation of such a complex phenomenon as senior symbolism.

The central gnoseological category in symbolism is Symbol, which encompasses a set of certain concepts. First of all, with the help of these concepts one who perceives the reality can recreate or create it in multiple worlds of the author's imagination. Secondly, they can be compared to the space-time system of a novel as they can simulate the space-time continuum depending on the time coordinates or the cycle of seasons, days, etc. (for example, in works by Valery Bryusov and Fedor Sologub). Thirdly, through realizing their communication function, they enable and sometimes force the reader to plunge in the author's world thus making the reader a part of the actual creative process [6].

We would like to point out the fact that even in its beginnings, symbolism drew attention and was considered by both its critics and supporters as a phenomenon that goes beyond the purely aesthetic framework. Indeed, the ideological crisis, the loss of the matter, the apprehension and the anticipation of future disasters and global apocalypse, which were perturbing to many, - the response to all this had to be something broad, comprehensive, enabling to set and achieve a grand purpose [7, 8, 9]. And if philosophy is the study of all things and all their meanings, and the need to build a comprehensive picture of the world, or the need to search for the truth, is a principal spiritual need of a human being, who for the sake of satisfying this need is often willing to sacrifice the others. This would be exactly the scale of tasks that symbolist writers set to themselves (which they often declare in their works), which fundamentally differentiates them from their predecessors, the overwhelming majority of whom would deal with exclusively aesthetic tasks $[10,11,12]$.

In fact, they are trying to adequately respond to the challenge of the time: theoretical reasoning is no longer satisfying as it is not relevant to practical life and diverts one from the reality into the sphere of abstract philosophizing failing to achieve the main purpose, i.e. the ability to influence the reader. That is why there is feedback: it is through (first aspect) the philosophical perception of the reality, through (second aspect) the proper artistic expression of acquired views, and (third aspect) the practical method of evocation that one can produce a profound effect on the world.

Symbolists believe that neither realists (naturalists) nor disciples of the pure art concept are capable to perceive the entire spectrum of capabilities that a work of art possesses and thus cannot exploit them. The tasks they set to themselves are not complex enough (realists focus on the object while those who support the idea of art for art's sake focus on the subject). Both of the above underestimate the philosophical value of art [13, 14]. Only through the integration of the subject-object

* Corresponding author: evgenvkor@mail.ru 
relationship in a literary work one can build an adequate picture of the world and transform or create it; that is why, one needs to know the truth in all of its subjectobject completeness. This is what symbolist art is capable of, which is opposed to its predecessors and which sets tasks of extreme importance. And this makes symbolism go beyond the aesthetic framework and gives it ontological, gnoseological and ethical meanings [15].

Using Andrey Belyi's words, “... Symbolism should follow a broader ideology: the symbolist principles should give us a solid philosophical system. Through symbolism one can contemplate the world." [16]

If one accepts the above-mentioned assumption, one can analyse the system of symbolism, just like any other doctrine, from the philosophical standpoint. In this case, the gnoseological aspect - in other words, identifying ways and means to search for the truth - comes to the foreground in works by both Russian and Western European symbolists.

Having analysed the writings of various authors, we can make the following assumption: For symbolists the subject of cognition is the overall substance of things. Symbolists believe that cognition is a natural immanent part of human existence. As all his life a person strives for freedom, for all the restrictions to be removed (especially in gnoseology), he naturally acquires the need for metaphysical knowledge [17, 18].

We believe it would be interesting to identify and understand the following aspects in the philosophical writings of symbolist authors: the roles of faith and mind in cognition, the rational vs. the irrational, subject-object relations; stages of the cognition process, what stimulates and determines it.

Let us look closer at the correlation between the rational and the irrational in the gnoseology of symbolism.

It is assumed that for symbolists the irrational only determines the search for the truth whereas the rational is given almost no thought; they respect intuitivism at best, thus one can conclude that empirical knowledge is false in its essence [19]. But how can one explain the following? Firstly, in terms of the form, how can one explain the careful attention to structure with which symbolists create their works (from the delicate finish they give to their verses to the detailed descriptions of scenes in dramatic pieces)? Secondly, in terms of the content, how can one explain the fact that symbolists created a great deal of lyric poems describing landscapes or historical and social works, or the fact that some of Maurice Maeterlinck's writings are devoted to natural philosophy?

As a matter of fact, symbolists do accept empirical knowledge as long as it is not overemphasized. It is one of the steps on the steady way to the Truth, and that is how one should take it. And the next step would be trying to understand the meaning of the things that happened by way of rational (abstract) thinking. And the abstract thinking opens the way for the third step - i.e. intellectual contemplation, as Vladimir Solovyov referred to it $[20,21,22]$.

Talking about creative writing, it would be worth noting that with the rise of the problem of purity in comprehending the incomprehensible Russian and Western European symbolists (in particular, M. Maeterlinck) went their separate ways.

M. Maeterlinck's characters, balancing in between existence and non-existence, cherish a vague hope that the Truth can be materialized. In his works Nonexistence crashes into the world of Being, which is realized through the image of death or the tragedy of everyday life. In its turn, Existence crashes into the realm of the non-creating and non-being while emphasizing, pre-making, creating it in the process of cognition. By placing his characters in the borderline state, Maeterlinck admits there is nothing that would be non-pure, beyond the limits. He believes that the objectivation of the Truth is pre-determined by the actual human progress. It could be for this reason that the Russian symbolist Nikolay Minsky, founder of meonism, gave him the nickname "Maurice the Happy Man".

Compared with their Belgian counterpart, Russian symbolists were more consistent and radical. They pay a great deal of attention to the creation: "Abstraction delights me // Through it I create the world..." (Zinaida Gippius proclaims), "I am the God of the mysterious world..." (Fedor Sologub says to the reader), "You are your own God, you are your own neighbour.// So be your own Creator..." (Dmitry Merezhkovsky appeals). This premise superimposed on the renaissance thesis, which is also popular in German romanticism, i.e. "you created = you perceived", produces the following result: If you cannot perceive the Truth, you can create it. This reveals another aspect in understanding the process of cognition when the subject merges with the object.

This is what reveals a peculiar aspect of the evocation method: if the poet is, indeed, the Creator, who is the reader, who, in Valery Bryusov's opinion, should be put under a charm with word symbols arranged in a certain pattern, who should be tricked into the realm of monopolized Truth, i.e. the realm of Nonexistence if we go back to Maeterlinck's terminology.

What comes most close to the problem of searching the truth and sometimes results from it is the idea of creative cosmogenesis in the poetics of senior symbolism.

For example, in the writings of Fedor Sologub the motive of correspondences plays a decisive role, which we view as a sound example of the difference between how the poet sees the essence of nature and Arthur Schopenhauer's approach, even that the critics stated that the German philosopher had a direct influence on the poetry of Russian symbolists [23, 24].

One finds this motive in Fedor Sologub's "Under the bird-cherry tree, in bloom...", which verse makes a part of the Correspondences series published in 1907. The author draws a parallel between the author's personal perception of nature and the things from the world of humans. Apart from the above mentioned piece, another work from this series in line with the given timeline includes "There are correspondences in everything...".

The author of the above verse, in the very first quatrain, points out the correspondence between things happening to a person and how they evince themselves in external reality: 
...In return for happiness and pain

Both laughter and tears we will find.

Then Sologub takes his character beyond the realm of human relationships and makes an attempt to find a natural phenomenon that would express the character's state of mind:

...And if we long for consolation,

We run a long way away from people.

Amidst the woods, amidst the fields -

There is peace, empty mind, oblivion.

Who is in exile, he knows no languor

Or contempt or vengeance.

In this case we come across the descriptions of nature that can hardly be regarded as positive (peace, empty mind, oblivion).

One should note the following here: the correspondences implied by the author are not between the human world and the realm of nature but rather between the realm of nature and the inner world of the character, and the human world serves as a contrast being beyond the correspondences, something one should "run away" from. Thus, we can say that when the character blends in with the nature, he loses a connection with the human world and the feelings he experiences become similar to the things in nature. He loses awareness and finds peace thus freeing himself from experiencing either happiness or pain, which seems to be in concordance with Schopenhauer's approach.

However, the last four lines add a new tone to the picture:

...So, by entrusting ourselves to nature,

In defiance of what is meant to be,

In everything we shall find correspondences

To our spirit, to our freedom.

One should note what correspondences to the nature the author identifies in this verse: both the character and the nature should act "in defiance of what is meant to be", only in this case there will be affinity between them in terms of spirit and freedom. To elaborate on this idea, we shall give another example of correspondence by citing the verse "My grass-grown yard...":

...And the wind that gusts at times

Makes the nettle flutter and swing,

Plays with it, just like

The freakish fate plays with me...

So, the fate forces the character and the nature go against their will. In the above-mentioned context, we can compare the fate to the determinism of events, which have broad interpretations in Schopenhauer's works. The latter believed that there is no free will either in terms of nature or in terms of how one behaves or acts, that everything is determined by cause and effect, so no freedom can be possible. But even when we look at the verse "Under the bird-cherry tree, in bloom...", we see how Sologub's views differ from Schopenhauer's approach. And in "There are correspondences in everything..." this difference in views is quite profound. The main character is looking for a correspondence to his spirit and his freedom in the natural world designed pursuant to the law of foundation, in which, according to the German philosopher, it is not to be found.
The way the space-time relationships are built in the context of such correspondences is quite peculiar.

The natural world and the inner world of the narrator exist in parallel (i.e. they are independent and have no influence on each other), neither of them can imagine that the other one exists, and only when the author is feeling creative they meet each other in time and space.

This is not the only difference that exists. Another one would be as follows: On the way towards lower spheres of life the character reaches a certain threshold where he stops, and he has no intention to go further to disappear in will and death. So the radical appeal of Arthur Schopenhauer and, especially, Eduard von Hartmann is left without attention.

As a conclusion, it is to be noted that Fedor Sologub did not view the natural realm simply as a cause-andeffect system, as per Schopenhauer's approach. Sologub distinguishes certain things in nature that correspond to the spirit (it should be noted here that under the "spirit" the author understands a kind of a tool through which the subject can realize his creative potential) and the freedom of the author's personal world.

It is in connection with the above-mentioned that we understand the meaning behind the questions about the essence of being that the author raises in many of his works.

For example, in the verse "Wicked earthly languor..." the main character is seeking to understand how things are in reality:

Wicked earthly languor

Wicked earthly existence

Are you the God's dream

Or nobody's ?..

If viewed from the standpoint of the German philosopher, the above-mentioned question would make no sense because if the world only exists as a part of the subject's imagination, the "wicked earthly languor" is not "God's" or "nobody's" dream but a dream of the "I" of the main character. It means that the author sees the "earthly existence" as going beyond the subjective perception. In the last quatrain, the character poses a direct question:

By whose creative will

The vanity of life

Is made inseparable

From tireless strive?

Here we deal with three manifestations of the existence: somebody's "creative will", "tireless strive" and "the vanity of life". Using Schopenhauer's discourse, they can be deciphered as follows: tireless strive is a will to live in a permanent state of realization as the essence of all things; the vanity of life is a representation of the external reality, something that is continuously changing, growing and dying; and all together the make the defining "wicked earthly existence". The creative will in this context stands for the very "World Will". In this case, however, what is the author, who is well familiar with the discourse of the "great pessimist", trying to achieve by posing a question of this kind? Perhaps, this is how the author tried to resolve one of the most apparent contradictions inherent in Schopenhauer's discourse: What is the teleology of 
the Will itself? Why does it become objective in personal manifestations? If so, wouldn't that indicate that it has its own mind? And here is why "creative will". It would be worth reminding here that it is in this that the author finds similarity between his spirit and the nature.

The verse "I don't understand how..." is another indication of the fact that the author is not satisfied with the way Schopenhauer's theory explains how the universe is designed. The author expresses it in the very first stanza:

I don't understand how

In deathly and poor nature

By some magic will

Life arises in its triumph...

The author establishes that nature is dead as it is meaning that the force of nature, which we compared to the World Will, does not bring a true "life". Consequently, if there are two lives, one may assume there exist two generative forces. The following quatrain supports this assumption:

I see the eternal nature

In the inevitable grip of forces

But then who was that who made

Inspiration and freedom a part of life ?..

The "eternal nature" is subject to the expressions of will in the form of physical forces, which conforms to Schopenhauer's views. So it seems to be quite natural that the author wonders about the origin of "inspiration" (in other words, the state of feeling creative or the "spirit" as mentioned before), and the "freedom". Even in this case we can say that that somebody appears to have vast opportunities to realize "wicked will", "in defiance of what is meant to be", as a special force of nature. In the last four lines, the author indicates what the principal attribute of that force is:

But I am not meant to understand how

In deathly and poor nature

By magic will

Spiritual life is recreated in its triumph.

In Sologub's poetry, the world of eternal nature defined by the World Will, which evinces itself as a cause-and-effect paradigm, is lacking a true spiritual life. It means that the Will that begets physical life appears to be absolutely powerless here. At the same time, the narrator, as he dives into and disappears in the natural world, finds correspondences to his feelings that are somewhat different than those produced by the Will. First, it is the ability to go against what is determined by the Will, the ability to realize one's creative potential and free self-expression. These three attributes describe a special force that would be antagonistic in the way it manifests itself to the World Will of the German philosopher. Another attribute should be pointed out here: If this force is capable to influence the "eternal nature" and resist (or shape) the eternal will, it means that it may also be eternal, i.e. being beyond the timespace paradigm.

In fact, both the above-mentioned "forces" have an effect on the creative potential of the narrator, on his gnoseological ambitions. We think that the author himself came up with a good name to refer to them in his verse "To drag oneself wearily along the desert of life...". Pondering over the illusiveness of the world, the illusiveness of the sameness of his minds and the continuous evolution of his character's views, the poet declares:

...And the burning thoughts about the secret purpose

Of the all-being

Shall fade away, like the noise made by a pipe

That falls in the stream, hits the bottom and breaks.

We believe that it is the "all-being", which is aiming at its secret goal and which will always be an enigma changing all the time that most accurately defines all the things happening in the world and their generative forces.

The strive to comprehend the incomprehensible "allbeing" describes the state of mind of a person who is seeking to uncover his internal need for metaphysical knowledge, as viewed by symbolist poets, while the author should try and engage the reader into the process of creating the Truth. Thus, one can summarise that in this case we witness how the two elements - the lifeaffirming one and the life-denying one - are fighting each other, which is one of the fundamental principles of symbolism.

\section{References}

1. A.S. Apevalov, Education. Science. Academic personnel 7, 163-166 (2012)

2. S.A. Boitsova, /Bulletin of the Tambov University. Series: The humanities 3-1, 210-214 (2006)

3. D.M. Dremlyugin, The problem of truth in philosophy and science ; Kopnin National Seminar for Young Scientists. Ser. Proceedings of the Tomsk State University. Philosophy. Tomsk State University, 43-44 (2008)

4. A.P. Kazarkin, Bulletin of the Tomsk State University. Philology 2, 76-81 (2012)

5. A.A. Lvov, Bulletin of the Saint Petersburg University. Philosophy and Conflictology 3, 316325 (2017)

6. E.V. Volzhenina, Bulletin of the St.Tikhon's Orthodox University. Series 2: History. History of the Russian Orthodox Church 1, 97-106 (2014)

7. V.A. Matveenko, Philosophical Thought 11, 77-97 (2015)

8. A.M. Malivskyi, Anthropological Measurements of Philosophical Research 6, 142-150 (2014)

9. N.I. Petrunok, Anthropological Measurements of Philosophical Research 6, 113-124 (2014)

10. K.M. Magomedov, Islamic Studies 7, 46-59 (2016)

11. D.D. Chernyshevskaya, Bulletin of online conferences in medicine 5(12), 1780 (2015)

12. O.G. Shevchenko, Historical, philosophical, political and legal sciences, cultural studies and art. Theoretical and practical issues 4-2, 190-195 (2011) 
13. F.K. Sologub, Complete set of works in three volumes. Volume 1. 1877-1892 (S.Petersburg, Nauka, 2012)

14. A.A. Kazenina, Bulletin of the Tambov University. Series: Social sciences 1, 73-78 (2016)

15. J.L. Dornan, Cambridge Archaeological Journal 14, 1, 25-36 (2004)

16. N.A. Khrenov, Legacy 1, 28-49 (2015)

17. R.A. Migurenko, Bulletin of Tomsk Polytechnic University, 319(6), 117-122 (2011)

18. G.G. Khazagerov, Sociology Journal 3, 5-28 (2001)

19. A.M. Malivskyi, Anthropological Measurements of Philosophical Research 5, 109-119 (2014)

20. V.A. Kornev, Orthodox scholar in today's world / Proceedings of the $2^{\text {nd }}$ International Science Conference, 70-74 (2013)

21. A.F. Polomoshnov, Scholar from the South of Russia 3, 97-105 (2014)

22. N.G. Yurina, Solovyov Studies 3, 67-81 (2012)

23. A. Schopenhauer, The world as will and representation. Collected edition: In 5 volumes. (Moscow, 1993)

24. R.S. Klyuikov, S.F. Klyuikov, World-outlook aspects of development of the historical process and the spiritual culture formation Peer-reviewed materials digest (collective monograph) published following the results of the XCVIII International Research and Practice Conference and I stage of the Championship in Art History, History, Philosophy, Culturology, physical culture and sports, 36-39 (2015) 